Bangladesh Journal of Neuroscience 2014; Vol. 30 (1) : 45-49

\title{
Evaluation of C Reactive Protein in Acute Ischemic Stroke
}

\author{
KAZI GIASUDDIN AHMED ${ }^{1}$, ABU SALEH MD BADRUL HASAN², BIPLOP KUMAR ROY ${ }^{3}$, \\ MD RAFIQUL ISLAM ${ }^{4}, M D$. RUHUL QUDDUS ${ }^{5}$
}

\begin{abstract}
:
Background: Stroke is a dreadful health hazard all over the world as well as in our country. The relationship between serum C-reactive protein (CRP) level and acute ischaemic stroke is not well studied especially in Bangladesh. Aims and Objectives: To evaluate the association of C-reactive protein (CRP) in acute ischemic stroke .Materials and Methods: This case-control study was carried out in the Department of Neurology, Bangabandhu Sheikh Mujib Medical University (BSMMU), Dhaka during the period from January 2006 to December 2007. A total of 30 acute ischaemic stroke patients were included in the case group. Another 30 age and sex matched and apparently healthy persons without any stroke were taken as controls. Results: The stroke patients [21 (70.0\%) male; mean age, 56.3 (SD \pm 13.7$)$ years] and control subjects [25 (83.3\%) male; mean age, 53.4 (SD \pm 9.9) years] were similar in age and sex $(p>0.05$ each). CRP level was significantly higher in acute ischaemic stroke patients than that of control [42.06 ( $S D \pm 21.26) \mathrm{mg} / \mathrm{L}$; vs 4.30 ( $S D \pm 0.072$ ) $\mathrm{mg} / \mathrm{L}$; $p<0.001]$. CRP was found positive in 28 (93.7\%) stroke patients and none of the control subjects. CRP was 16 times significantly higher in stroke patients than that of control subjects $(O R=16.00 ; 95 \% C l=4.18-61.22 ; p<0.001)$. Conclusion: This study confirms that CRP is elevated in acute ischaemic stroke. More local studies are required regarding the significance of CRP as a risk factor for acute ischemic stroke.
\end{abstract}

Introduction:

World Health organization defined stroke as a clinical syndrome occurring due to sudden cerebral dysfunction, producing focal or global neurological deficit, persisting for more than 24 hours or the patient dies within 24 hours, vascular in origin, nonepileptic and non-traumatic in nature ${ }^{1}$. Stroke remains third leading cause of death after heart disease and cancer after the age of $40^{2}$. About 4 million deaths per year worldwide are due to stroke, three-quarters of them in developing countries ${ }^{3}$.

Of all strokes, 85 percent are ischaemic infarction and 15 percent are haemorrhage; thus ischaemic cerebrovascular disease accounts for a substantial proportion of all strokes. Although the proximate cause of most brain infarcts is thrombus formation, atherosclerosis is the chief underlying cause ${ }^{4}$. C- reactive protein (CRP), one of the acute-phase reactants, is an indicator of underlying systemic inflammation and a novel plasma marker of atherothrombotic disease ${ }^{5}$. Furthermore, elevated plasma levels of $\mathrm{C}$-reactive protein are not disease specific but are sensitive markers produced in response to tissue injury, infectious agents, immunologic stimuli, and inflammation ${ }^{6}$.

Elevated blood levels of C-reactive protein (CRP) are associated with an increased risk of therosclerotic vascular disease including stroke ${ }^{7}$. However the role of CRP in the etiology and prognosis of ischemic stroke remains to be clearly defined $^{8}$. One hypothesis is that CRP plays a direct causal role in the pathogenesis of atherosclerosis by promoting endothelial cell adhesion molecule expression, monocyte recruitment or complement

1. Assistant Professor, Department of Neurology, National Institute of Neurosciences \& Hospital, Dhaka.

2. Assistant Professor, Department of Neurology, Dinazpur Medical College \& Hospital,Dinazpur.

3. Associate Professor, Department of Neurology, Sylhet MAG Medical College \& Hospital,Sylhet

4. Professor, Department of Neurology, Bangabandhu Sheikh Mujib Medical University, Dhaka, Bangladesh

5. Assistant Professor, Department of Neurology, Shaheed Abu Naser Hospita, Khulna 
activation, or by mediating low density lipoprotein cholesterol uptake by macrophages ${ }^{9}$.

This "atherogenic hypothesis" is consistent with prospective observational studies of apparently healthy individuals as well as patients with established vascular disease, including stroke which have shown that elevated blood concentrations of CRP are a significant predictor of future cardiovascular events, independent of conventional vascular risk factors ${ }^{10}$.

Elevated blood concentrations of CRP during the acute phase of ischaemic stroke event primarily reflect the extent of cerebral ischaemic injury and its complications ${ }^{11}$. Higher values of C-reactive protein (CRP) are significantly associated with large infarct size and worst outcome ${ }^{12}$. So C-reactive protein might indicate the inflammatory status during the acute phase of ischaemic stroke. Use of plasma CRP levels may aid indentifying a potentially large number of men and women who are at risk for cerebrovascular events ${ }^{6}$.

As C-reactive protein is a marker of inflammation and if we target for intervention against inflammatory response in ischaemic stroke may halt the disease progression and improve outcome. The purpose of the study is to find out the association of $\mathrm{C}$-reactive protein in ischemic stroke.

\section{Materials and Methods:}

This was an observational case control study carried out in the Department of Neurology in collaboration with the Department of Microbiology and Immunology, Bangabandhu Sheikh Mujib Medical University (BSMMU), Dhaka during the period from January 2006 to December 2007.

A total of 30 patients were included in the study group whom met the inclusion and exclusion criteria. Inclusion were all acute ischaemic stroke $(<4$ weeks duration) proved clinically and confirmed by neuroimaging (CT/MRI of brain), aged more than 30 years and either sex. Patients with history of acute myocardial infarction, venous thrombosis, myeloproliferative diseases, malignancy, rheumatological diseases, connective tissue diseases, recent surgery (within one month) and recent infection (within one month) were excluded.
A total of 30 age and sex matched and apparently healthy persons were taken as controls. Controls never suffered from stroke and came in neurology outpatient department for nonspecific disorders and symptoms like anxiety neurosis, myalgia, burning limbs, tingling numbness, headache and somatoform disorders and had no clinically apparent infection or inflammation or sign of neurological deficit.

Written consent was taken after explaining the study procedure and aims of the study. Detail history was taken about age, sex, hypertension, diabetes, smoking habit, cardiac disease and oral contraceptive pills. They were also asked about febrile infection or productive cough, diarrhoea and dysuria. They were clinically evaluated for the presence of sinusitis, diabetes, hypertension, and tuberculosis, pneumonia, bronchitis. For detection of lymphadenopathy cervical, supraclavicular, axillary and inguinal groups of lymph nodes were searched for. They were also clinically evaluated for presence of any valvular and ischemic heart disease. All of them were investigated for serum C-reactive protein, complete blood count, serum creatinine, random brood sugar, serum lipid profile, ECG and chest Xray P/A view.

Measurement of C-reactive protein in serum was estimated by Nephelometric System by using commercial kit (DADE BEHRING BN 100, USA) in the Department of Microbiology and Immunology of Bangabandhu Sheikh Mujib Medical University.

Data were processed and analyzed with the help SPSS (Statistical Package for Social Sciences) 11.0 version for windows. All quantitative data were expressed as mean and standard deviation; and comparisons between the groups of patients were performed by unpaired $t$ test. Qualitative data were expressed as frequency and percentages; and comparison was done by the Chi-Square $\left(\div^{2}\right)$ test or Fisher's Exact Test. Any probability value of less than $5 \%(p<0.05)$ was considered statistically significant.

\section{Results:}

The age of the stroke patients ranged from 35 years to 80 years with the mean age of $56.3(S D \pm 13.7)$ years; while the age of the control subjects ranged 
from 32 years to 71 years with the mean age of 53.4 (SD \pm 9.9 ) years. There was no significant difference was observed between the mean age of case group and control group ( $p>0.05$ ) (Table-I).

Among 30 stroke patients 19 (63.3\%) were above 50 years of age and $11(36.7 \%)$ were less than 50 years. Among control subjects $16(53.3 \%)$ were above 50 years and $14(46.7 \%)$ patients were below 50 years. There was no significant difference of age group between case and control subjects $(p>0.05)$ (Table-I).

There were $21(70.0 \%)$ males and $9(30.0 \%)$ females in stroke patients group; while 25 (83.3\%) males and $5(16.7 \%)$ females in control group. There was no significant difference of sex between the groups ( $>0.05)$ (Table-l).

C-reactive protein (CRP) level of stroke patients ranged from 3.60 to $65.00 \mathrm{mg} / \mathrm{L}$ with the mean of $42.06(\mathrm{SD} \pm 21.26) \mathrm{mg} / \mathrm{L}$; while CRP level of the control subjects ranged from 3.20 to $5.60 \mathrm{mg} / \mathrm{L}$ with the mean of 4.30 (SD \pm 0.072$) \mathrm{mg} / \mathrm{L}$. CRP level was significantly higherin stroke patients than that of control subjects $(t=9.723 ; p<0.001)$ (Table-II).

CRP was positive in $28(93.7 \%)$ stroke patients and none of the control subjects. CRP was positivity was 16 times significantly higher in stroke patients than that of control subjects $(O R=16.00 ; 95 \%$ $\mathrm{Cl}=4.18-61.22$; $\mathrm{p}<0.001$ ) (Table-II).

Table-I

Distribution of study subjects by demographic features

\begin{tabular}{lccc}
\hline Demographic features & \multicolumn{2}{c}{ Study Group } & p-value \\
\cline { 2 - 3 } & Case $(n=30)$ & Control $(n=30)$ & \\
\hline Age & & & \\
Mean (SD) years & $56.3(\mathrm{SD} \pm 13.7)$ & $53.4(\mathrm{SD} \pm 9.9)$ & ${ }^{*} \mathrm{p}>0.05$ \\
$31-40$ years & $7(23.3 \%)$ & $3(10.0 \%)$ & \\
$41-50$ years & $4(13.3 \%)$ & $11(36.7 \%)$ & ${ }^{\dagger} p>0.05$ \\
$51-60$ years & $6(20.0 \%)$ & $10(33.3 \%)$ & \\
$61-70$ years & $10(33.3 \%)$ & $5(16.7 \%)$ & \\
$71-80$ years & $3(10.0 \%)$ & $1(3.3 \%)$ & \\
& & & \\
Sex & $21(70.0 \%)$ & $25(83.3 \%)$ & \\
Male & $9(30.0 \%)$ & $5(16.7 \%)$ & \\
Female &
\end{tabular}

* Unpaired $t$ test, ${ }^{\dagger}$ Fisher’s Exact test, and ${ }^{\ddagger}$ Chi-Square $\left(\div^{2}\right)$ test were employed to analyse the data.

Table-II

Distribution of the patients by status of C-reactive protein

\begin{tabular}{lcccc}
\hline C-reactive protein & \multicolumn{2}{c}{ Study Group } & Odd ratio $(95 \% \mathrm{Cl})$ & * $\mathrm{p}$-value \\
\cline { 2 - 4 } & Group-A $(\mathrm{n}=30)$ & Group-B $(\mathrm{n}=30)$ & & \\
\hline Positive & $28(93.7 \%)$ & $0(0.0 \%)$ & $16.0(4.2-61.2)$ & $\mathrm{p}<0.001$ \\
Negative & $2(6.7 \%)$ & $30(100.0)$ & & \\
Mean $( \pm \mathrm{SD}) \mathrm{mg} / \mathrm{L}$ & $42.06(\mathrm{SD} \pm 21.26)$ & $4.30(\mathrm{SD} \pm 0.072)$ & & $\mathrm{p}<0.001$ \\
\hline
\end{tabular}

*Fisher's Exact test and TUnpaired $\mathrm{t}$ test were done analyse the data. $\mathrm{SD}=$ standard deviation; $\mathrm{Cl}=$ confidence interval, $\mathrm{OR}=\mathrm{Odd}$ ratio, CRP negative: $<6 \mathrm{mg} / \mathrm{L}$, CRP positive: e" $6 \mathrm{mg} / \mathrm{L}$ 


\section{Discussion:}

Several case-control studies with ischemic stroke patients have indicated that recent infections are a possible risk factor for ischemic stroke ${ }^{13-16}$. In particular; there is increasing evidence that inflammatory processes are involved in cerebral ischemia. There is growing evidence that $\mathrm{C}$-reactive protein (CRP), a peripheral marker of inflammation, is also a marker of generalized atherosclerosis ${ }^{15}$. This relationship between inflammation and atherosclerosis make CRP a potential marker for prognosis after vascular events and a potential predictor of future vascular events. The present study was conducted in the Department of Neurology, Bangabandhu Sheikh Mujib Medical University (BSMMU), Dhaka.

The present study showed that mean age of the cases was 56.3 (SD \pm 13.7 ). This finding is consistent with the findings of a previous study of Ropper and Brown ${ }^{2}$ where the average age was 58 (SD \pm 12 ) years. Eslami et al. ${ }^{17}$ found that $55 \%$ of stroke patients were in the age group above 60 years, $35 \%$ of the patients were in the age group 40-60 years and $10 \%$ of stroke patients were in the age group below 40 years. Syed et al. ${ }^{18}$ reported that $47.1 \%$ of stroke patients were in the age group $55-69$ years, $24.9 \%$ of the patients were in the age group above 69 years, $21.6 \%$ of the patients were in the age group $40-54$ years and $6.4 \%$ of stroke patients were in the age group below 40 years.

Seventy percent of this study subjects were male and $30 \%$ were female. In this regards Syed et al. ${ }^{18}$ found $62.6 \%$ of patients were male and $37.2 \%$ of patients were female; and Guerrero-Romero and Rodríguez-Morá ${ }^{19}$ found $62.7 \%$ of patients were male and $37.3 \%$ of patients were female. Shaikh et al. ${ }^{20}$ found $61 \%$ of patients were male and $39 \%$ of patients were female in their series. This difference found in the study may be due to the attitude of our society that the females are less frequently brought to the hospitals for treatment.

In this study serum CRP level was found to be elevated in $28(93.3 \%)$ stroke patients with mean CRP value was 42.06 (SD \pm 21.26$) \mathrm{mg} / \mathrm{L}$; whereas among the control it was $4.30(\mathrm{SD} \pm 0.72) \mathrm{mg} / \mathrm{L}$. These findings are consistent with several studies ${ }^{21-}$
23. The possible explanations are 1) CRP concentration may reflect the degree of stroke severity, correlating with the degree of inflammation directly consequent to cerebral infarction; 2) CRP concentration may indicate underlying unstable atherosclerotic disease; 3) CRP may be raised as a consequence of secondary complications of stroke at the time of sampling 22 .

In this study 2 stroke patients were negative for Creactive protein value. Grau ${ }^{24}$ found about $25 \%$ of patients with first ever ischaemic stroke had normal levels of CRP after stroke. It might be due to the variability of the degree of inflammatory response to ischemic stroke ${ }^{5}$.

This study was not without limitations. The limitations were 1) The study was not prospectively designed to assess the effect of CRP on long term outcome of ischaemic stroke; 2) This study was conducted in a tertiary care hospital.

Conclusion: This study confirms that C-reactive protein is elevated in acute ischaemic stroke. Further more local studies are required with higher sample size regarding the significance of CRP as a risk factor for acute ischemic stroke.

\section{References:}

1. Aho K, Harmsen P, Hatano S. Cerebrovascular disease in the community: results of a WHO collaborative study. Bull WHO 1980; 58: 113-30.

2. Ropper $\mathrm{AH}$, Brown RH. Cerebrovascular Disease. In: Adams and Victor's Principles of Neurology, $8^{\text {th }}$ edn. New York: McGraw-Hill Company. 2005; pp. 660-746.

3. Murray CJL, Lopez AD. Mortality by cause for eight regions of the world: global burden of disease study. Lancet 1997; 349:1269-76.

4. Ross R. Atherosclerosis, an inflammatory disease. N Eng J Med 1999; 340:115-26.

5. Gabbay C, Kushner I. Acute phase proteins and other systemic responses to inflammation. N Eng J Med 1999; 340: 448-54.

6. Rost NS, Wolf PA, Kase CS, Kelly HM, Silibershatz $\mathrm{H}$, Massaro JM, et al. Plasma concentration of $\mathrm{C}$-reactive protein and risk of 
ischaemic stroke and transient ischaemic attack: The Framingham Study. Stroke 2001; 32: $2575-79$.

7. Lagrand WK, Visser CA, Hermens WT. Creactive protein as a cardiovascular risk factor. More than an epiphenomenonan. Circulation 1999; 100:96-102.

8. Yeh E, Anderson V, Pasari V. C-reactive protein. Linking inflammation to cardiovascular complications. Circulation 2001; 104: 974-5.

9. Zwaka TP, Hombach V, Torzewski J. Creactive Protein mediated low density lipoprotein uptake by macrophages. Implications for atherosclerosis. Circulation 2001; 103: 1194-7.

10. Papa F, Di Napoli M, Bocola V. C-reactive protein in ischemic stroke: an independent prognostic factor. Stroke 2001; 32: 917-24.

11. Muir KW, Weir CJ, Alwan W. C-reactive protein and outcome after ischemic stroke. Stroke 1999; 30: 981-85.

12. Petty GW, Brown RD, Whisnant JP. Ischemic stroke subtypes: a population-based study of functional outcome, survival and recurrence. Stroke 2000; 31:1062-8.

13. Feigin VL, Lawes CM, Bennett DA, Anderson CS. Stroke epidemiology: a review of population-based studies of incidence, prevalence and case-fatality in the late $20^{\text {th }}$ century. Lancet Neurol 2003; 2(1): 43-53.

14. Feigin VL. Stroke epidemiology in the developing world. Lancet 2005; 365: 2160-61.

15. Ridker PM, Danielson E, Fonseca FA, Genest J, Gotto AM, Kastelein JJ. Rosuvastatin to prevent vascular events in men and women with elevated C-reactive protein. N Engl J Med 2008; 359: 2195-207.
16. Petrea RE, Beiser AS, Seshadri S, KellyHayes M, Kase CS, Wolf PA. Gender differences in stroke incidence and poststroke disability in the Framingham heart study. Stroke 2009; 40(4): 1032-37.

17. Eslami V, Sahraian MA, Gheini MR, Motamedi $M$, Yazdani T. Impaired glucose metabolism in nondiabetic patients with acute stroke. Iranian Journal of Neurology 2008;7(23):246-58.

18. Syed NA, Khealani BA, Ali S, Hasan A, Akhtar $\mathrm{N}$, Brohi $\mathrm{H}$, et al. Ischemic Stroke Subtypes in Pakistan: The Aga Khan University Stroke Data Bank. JPMA 2003; 53:584.

19. Guerrero-Romero F, Rodríguez-Morán M. Proteinuria Is an Independent Risk Factor for Ischemic Stroke in Non-Insulin-Dependent Diabetes Mellitus. Stroke 1999;30:1787-91.

20. Shaikh NA, Bhatty S, Irfan M, Khatri G, Vaswani AS, Jakhrani N. Frequency, characteristics and risk factors of Carotid Artery Stenosis in ischaemic stroke patients at Civil Hospital Karachi. JPMA 2010; 60:8-12.

21. Marquardt L, Ruf A, Mansmann U, Winter R, Buggle $\mathrm{F}$, Kallenberg $\mathrm{K}$, et al. C-reactive protein in ischaemic stroke. J Neurol Sci 2005; 236: 65-71.

22. Keith W, Cristopher J, WafaA, Lain B, Kennedy R. C-reactive protein and outcome after ischaemic stroke. Stroke 1999; 30: 981-85.

23. Hsu KO, Chung J, Chia H, Chen KK, Jen HC, Farzaneh S, et al. Relation of C-reactive protein to stroke, cognitive disorders, and depression in the general population: systemic review and meta-analysis. Lancet Neurol 2005; 4: 371-80.

24. Grau AJ. Infection, inflammation, and cerebrovascular ischemia. Neurology 1997; 49:47-51. 